\title{
O COMÉRCIO JUSTO NAS PRÁTICAS DE MARKETING SOCIAL DAS GRANDES EMPRESAS
}

\author{
Daniel Kamlot \\ Doutor em Administração pela Fundação Getúlio Vargas - FGV/SP \\ Professor pela Pontifícia Universidade Católica do Rio de Janeiro - PUC/RJ \\ danielkamlot@yahoo.com.br \\ Valentina Gomes Haensel Schmitt \\ Doutora em Administração pela Fundação Getúlio Vargas - FGV/SP \\ valentinaschmitt@hotmail.com
}

\section{RESUMO}

Este artigo descreve o contexto de inserção do Comércio Justo (CJ) nas práticas de Marketing Social das grandes empresas, ou mainstream das relações de comércio internacional. Após apreciação da literatura sobre os temas em questão, coletaram-se, durante 14 meses, dados relativos às práticas das grandes empresas, com o uso de ferramentas específicas, sendo feita uma análise do discurso que propiciou a avaliação de tal contento. Por meio de tal análise, nota-se que as empresas têm alguns pontos consonantes e outros nem tanto; nos discursos analisados, os responsáveis indicam que CJ não é filantropia, que ajuda a mostrar a preocupação existente com os produtores de menor porte, que a escala de compra de produtos do CJ ainda é reduzida diante do total dos negócios e que veem a sustentabilidade de maneira estratégica e transversal ao negócio, entre outros itens. Observando as práticas das grandes empresas estudadas, notam-se características similares em muitas delas, o que corrobora a atuação socialmente responsável, em conformidade com o Marketing Social. Há uma nova abordagem acerca da cultura e práticas organizacionais, no que concerne às relações de troca, atenção à pluralidade e aspectos até então relegados ao segundo plano, em particular para o meio empresarial. Destaca-se a compreensão de que a temática da inserção do CJ nas práticas mercadológicas do mainstream envolve a mudança de valores, formas de atuação e gestão organizacional.

Palavras-chave: Comércio justo; Grandes empresas; Mainstream; Marketing social.

\section{FAIR TRADE IN SOCIAL MARKETING PRACTICES OF LARGE CORPORATIONS}

\section{ABSTRACT}

In this paper we describe the context of Fair Trade in the Social Marketing practices in the mainstream (large companies) of international trade relations. After exploring literature about the subjects, we collected, over 14 months, data on big businesses practices, using specific tools, and made a speech analysis that led to the appreciation of such content. Through this analysis, we observed that the companies studied have some consonants and some obscure issues. Concerning the analyzed speeches, officials indicate that Fair Trade is not philanthropy, that it helps to expose the existing concern for smaller producers, that the Fair Trade products purchasing scale is still small compared to the total business and that they understand sustainability in a strategic way, among other items. By examining the practices of big companies, we observed the existence of similar characteristics in many of them, which corroborates the socially responsible action in accordance with Social Marketing. There is a new approach about culture and organizational practices, related to exchange relations, attention to diversity and aspects hitherto relegated to the background, both by academia and by business players. The inclusion of Fair Trade in the mainstream marketing practices involves changing values, forms of action, and organizational practices

Keywords: Fair Trade; Large enterprises; Mainstream; Social marketing. 


\section{INTRODUÇÃO}

As organizações são criadas para resolver problemas dos membros da sociedade, e são permeadas por uma pluralidade de interesses no cotidiano, decorrentes das interações entre grupos de interesses. Do contato entre os indivíduos, resultam as relações de trocas e de poder, que apresentam diferentes patamares de simetria e justiça. A complexidade ambiental apresenta desafios para a gestão organizacional e a configuração de suas práticas.

Considerando as assimetrias de poder existentes nas relações de troca internacionais entre as nações (cf. Stiglitz \& Charlton, 2005) - e os consequentes impactos no desenvolvimento de territórios -, constata-se que existem alternativas para a redução das externalidades negativas. No ambiente do comércio internacional, dados os diferentes estágios de desenvolvimento entre nações, ocorrem variações de percepção acerca de justiça e distribuição do poder (Adenauer, 2013). O ciclo vicioso, de trocas injustas, acarreta o retrocesso dos estágios de desenvolvimento dos menos privilegiados. Como exemplo, constata-se que produtores de países em desenvolvimento especialmente do setor alimentício -, representam parcela relevante dos fornecedores para os mercados consumidores de países desenvolvidos em segmentos específicos - como café e laranja. Contudo, as críticas acerca dos termos de troca aplicados acarretam negociações, muitas vezes, consideradas injustas pelos produtores, dado que há parcialidade nas relações, sendo afetadas predominantemente por interferências da dimensão econômica - uma vez que a dependência em recursos proporciona relações assimétricas (Schmitt, 2011).

Sendo o todo dependente das partes, torna-se inconcebível a ideia de sustentabilidade de relações que não sejam firmadas em critérios que considerem a pluralidade - observando aspectos econômicos, sociais e ambientais - e a conciliação de interesses individuais e coletivos. Por tal motivo, frequentemente surgem novas proposições de modelos de gestão e certificações como solução aos problemas organizacionais, entre os quais está o Comércio Justo (CJ), que resulta da formação de parcerias entre diferentes atores em busca de um meio para o acesso de produtores do Hemisfério Sul em mercados do Hemisfério Norte, sem a dependência de intermediários ou desvalorização da produção (Flo, 2008). Hoje, a proposta representa um movimento global sistemático de crescimento (Wielechowski \& Roman, 2012). Amparado em princípios de cooperação, sua origem está nos movimentos sociais ambientalista e de direitos humanos (Bucolo, 2003), ampliando a preocupação gerencial para além do enfoque em aspectos da ótica econômica ao inserir os temas social e ambiental na agenda.

Na prática da gestão, a temática do CJ vem a conjugar questões de mercado e sociedade visando ao desenvolvimento territorial sustentável (Gendron, Bisaillon, \& Rance, 2009). Isto porque se trata de uma proposta para o alcance do desenvolvimento, por intermédio da aplicação de técnicas diferenciadas de gestão organizacional, relações de troca, relações trabalhistas e interação com o ambiente geral. Para as organizações inseridas no CJ, são destacados os princípios da transparência nas relações entre os atores envolvidos - produtores, consumidores e organizações de suporte -, preço justo, respeito ao meio ambiente, condições justas de trabalho, respeito aos direitos das mulheres, defesa dos direitos das crianças e apoio ao desenvolvimento local e sustentável.

No ambiente empresarial, as práticas de CJ são gradativamente aproximadas da vertente de marketing voltadas aos aspectos sociais e ambiental, como no caso do Marketing Social. Este não comercializa, necessariamente, produtos ou serviços propriamente ditos, como ocorre no marketing convencional. Seu foco são os chamados produtos sociais, que podem ser ideias, práticas ou até objetos tangíveis (Kotler \& Roberto, 1992), como mostrado na Figura 1. As ideias compreendem crenças (percepção sobre algo concreto, sem avaliação), atitudes (avaliações positivas ou negativas de pessoas, acontecimentos, ideias ou objetos) e valores (percepções gerais do que é certo e errado). As práticas envolvem atos (ações únicas) e comportamentos (um padrão de atuação), e os objetos tangíveis são instrumentos para se estabelecer a prática social, muitas vezes sendo produtos físicos que podem acompanhar uma campanha com finalidade social. Ao contrário do setor comercial 
tradicional, que busca o lucro financeiro como meta primária, o Marketing Social tem como desígnio o ganho societário (Kotler \& Lee, 2008).

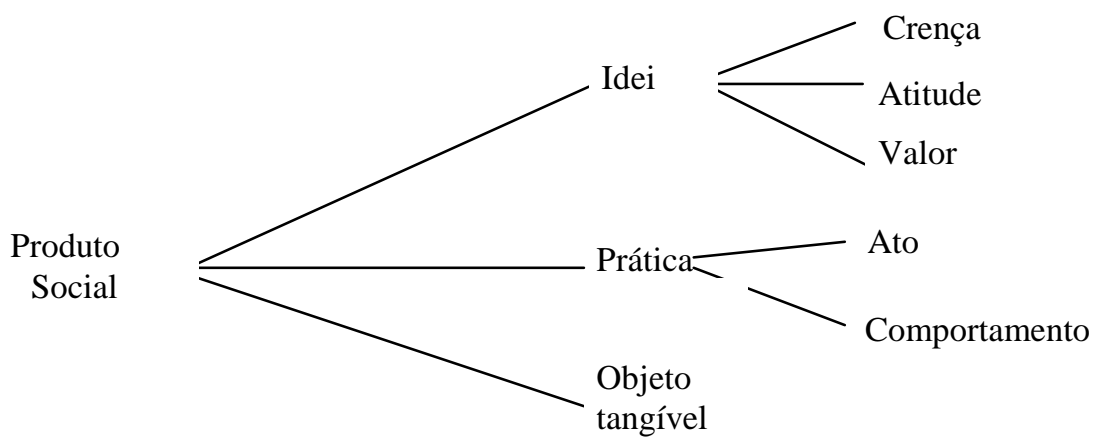

Figura 1 - Produtos sociais

Fonte: Kotler e Roberto (1992)

Dada a aproximação de conceitos, este artigo tem por objetivo descrever o contexto de inserção do CJ nas práticas de Marketing Social das grandes empresas, ou mainstream das relações de comércio internacional. A estrutura do texto está organizada de forma a apresentar o contexto de inserção e desenvolvimento do CJ, os aspectos que denotam a convergência entre CJ e práticas de Marketing Social, o CJ no mainstream, refletindo as demandas dos consumidores e as considerações finais sobre a temática.

\section{O CONTEXTO DE INSERÇÃO E DESENVOLVIMENTO DO CJ}

A proposta do CJ, ou Fair Trade, apresenta como diferencial a busca pela reconfiguração mais justa nas relações de trocas internacionais, refletindo aspirações sociais na ação econômica (Gendron et al, 2009), ao compreender que as organizações são criadas por indivíduos da sociedade que interagem nas constantes relações de troca, perante uma situação de interdependência sistêmica. As relações de troca entre as organizações e destas com o ambiente geral envolvem insumos diversos como bens naturais, força de trabalho, energia, capital e recursos de produção. Durante o intercâmbio existem variações, ou assimetrias, nas relações de poder entre os diversos atores por razões ou fontes diversas, que apresentam capacidade de impactar no desenvolvimento de territórios. Na essência do CJ reside o conceito de redução de assimetrias entre os hemisférios. Portanto, em teoria, quando respeitado o conceito básico, os produtores veem a si mesmos como profissionais autônomos e, a partir de então, da sua emancipação de regras e leis, decidem livremente os critérios que guiam as trocas - supostamente - justas (Flo, 2008).

A abordagem de que o comércio deve reforçar o bem-estar baseia-se na noção de que duas partes só realizarão negócios entre si voluntariamente se estes forem benéficos para ambas; caso haja, por exemplo, interferência governamental ou externa, haveria restrição na habilidade de se obter proveitos, o que prejudicaria no longo prazo a obtenção do bem-estar (Stiglitz \& Charlton, 2005). Para Francés, Gardó, Moreno, \& Granizo (2012, p.65), o CJ pode ser, ainda, entendido como um movimento não apenas econômico, mas também social, cuja serventia reside em garantir segurança e estabilidade nas condições comerciais aos produtores originários de países em desenvolvimento. Há, ainda, uma fundamentação ética relacionada ao conceito, que tem por norte a aplicação de critérios moralmente aceitos às chamadas "regras do jogo do comércio internacional".

Visando a consolidar o CJ, como esforços iniciais, foram estruturadas lojas nos países do Hemisfério Norte específicas para produtos condizentes com tal filosofia, e, em 1988, na Holanda, 
foi criado o primeiro selo que distinguiria os produtos (Bucolo, 2003; Flo, 2008). Em 1997, foi criada a Fair Trade Labelling Organizations International (Flo), uma organização centralizadora dos esforços de consolidação do CJ. A missão da Flo é de definir padrões de CJ, apoiar, inspecionar, certificar produtores desfavorecidos e harmonizar a mensagem do CJ pelo movimento (Flo, 2007). Um dos destaques dos esforços da organização foi que, em 2002, houve a criação da marca de certificação internacional, permitindo que produtos provenientes do CJ estivessem expostos em supermercados, de modo a serem facilmente identificados, distinguidos dos demais, assim como os procedimentos de comércio internacional simplificados.

No Brasil, mesmo diante do fato da origem do CJ datar da década de 1950, foi apenas na década passada (2000-2010) que a proposta passou a ganhar alguma força no país (Schneider, 2012). No Estado de Santa Catarina, por exemplo, no ano de 2009, quatro instituições vieram a integrar um projeto piloto, parte de um esforço de âmbito nacional do Serviço Brasileiro de Apoio às Micro e Pequenas Empresas (Sebrae) - para adequação à proposta. Contraditoriamente àquilo que no exterior já era cotidiano, para os brasileiros tratava-se de algo inovador.

Partindo do pressuposto de que o desenvolvimento territorial sustentável é amparado pelo tripé economia, sociedade e meio ambiente - seguindo a indicação de princípios concernentes a salários dignos (economia), organizações democraticamente organizadas (sociedade) e respeito a padrões ambientais (meio ambiente) (Gendron et al., 2009) -, existe a necessidade de conjugar os aspectos concernentes a essas diferentes esferas.

Em tese, a proposta de justiça no comércio reflete a ideia de como relações econômicas não eliminam, necessariamente, as de cooperação entre os agentes para a construção de regras e mobilização de recursos (Renard, 2003). O ato de compra reflete ações políticas e, conceitualmente, consumidores agregam valores individuais ao processo de escolha, incentivando, direta e indiretamente, os processos de gestão organizacional.

$\mathrm{Na}$ prática, ocorrem distorções do conceito base, pois, entre tantos problemas potenciais, algumas grandes empresas, comerciantes de produtos certificados com a origem do CJ, trazem concomitantemente oportunidades e riscos ao ideal, seja por erosão da identidade da marca, pela substituição da organização certificadora ou pelo crescimento do número de marcas e critérios de qualidade (Renard, 2005). A relação com grandes empresas, em muitos casos - ressalta Renard (2005) - abre margens para que, na negociação de vendas em grandes volumes, ocorra a redução de preços - até então justos - em médio ou longo prazo, afetando a relação com os consumidores - que até então consumiam os produtos em razão do conceito de justiça. $\mathrm{O}$ segundo risco decorre da possibilidade de substituição da organização certificadora oficial (Flo) por outras de menor critério. Simultaneamente, a multiplicação de critérios de qualidade confunde os consumidores, desperdiçando o tempo na compreensão e comparação entre as diferentes certificações e consecução dos objetivos de clareza, união e confiança (Renard, 2005).

De um ponto de vista teórico, o CJ visa a contribuir para o desenvolvimento sustentável como forma de hierarquizar as dimensões social, ambiental e econômica (Bisaillon, Gendron, \& Turcotte, 2005), além de evitar a promoção de danos aos consumidores (Cabrera \& Williams, 2012) e aos produtores (Wielechowski \& Roman, 2012). Em diversos países em desenvolvimento, tais danos aos produtores são percebidos devido à inabilidade dos respectivos governos em prover assistência na busca por padrões de qualidade estabelecidos, devido a problemas variados na infraestrutura, tecnologia e regulamentos (Stiglitz \& Charlton, 2005). A realidade demonstra que o CJ é um meio de passagem à sustentabilidade do sistema econômico liberal, como um meio de inserir produtores do Sul no sistema de comércio internacional (Bisaillon et al, 2005). Edward e Tallontire (2009) destacam que o CJ aspira à promoção do desenvolvimento, contudo existe o questionamento acerca da validade do uso do mercado para acelerar o desenvolvimento, bem como o tipo de desenvolvimento que pode ser gerado. Os padrões do CJ são um constante exercício de equilíbrio entre a satisfação dos interesses dos consumidores enquanto são gerados benefícios para os produtores. As implicações diretas são relacionadas ao alcance de objetivos de cada uma das partes - muitas vezes conflitantes -, e ao mesmo tempo, indiretamente, à dimensão em que cada um 
pode afetar o outro. Mesmo diante de tais fatos, há a crença entre os autores de que a adoção dos padrões do CJ e o processo de integração podem ser alcançados com reservas, mas o aspecto de destaque é que a expansão dos produtos certificados tem permitido ampliar o número de produtores aptos a usufruir dos seus benefícios.

Constata-se que há uma dicotomia entre a proposta apresentada e seu alcance prático. Se, em tese, há o interesse de conjugar os diversos aspectos que concernem à sustentabilidade - em termos econômicos, sociais e ambientais -, a prática demonstra que, em diversas situações, há a distorção conceitual, focando o CJ como uma alternativa para sustentabilidade financeira das organizações. No âmbito das relações comerciais, essa é uma modalidade de comércio que apresenta diferentes perfis de compradores - individuais e institucionais -, que variam em seus objetivos - entre missão e valores, qualidade ou aspectos mercadológicos - e, por consequência, práticas organizacionais (Raynolds, 2009). Tais variações refletem as ações organizacionais com enfoque direcionado para a perspectiva de contribuição socioambiental, ou meramente como uma atividade mercadológica.

Dado o conflito entre objetivos e resultados efetivos do CJ, Hayes (2008) afirma que a proposta é inferior a uma associação de livre comércio e às ajudas diretas, consequentes da distorção do preço premium pago pelo consumidor. Nesta perspectiva, o CJ é visto como uma forma paliativa para ajudar comunidades de territórios menos desenvolvidos, sendo o consumidor o patrocinador das benfeitorias sociais e ambientais, deslocando as demais responsabilidades inerentes ao estado ou ao setor privado.

O estereótipo voltado ao caráter paliativo resgata a problemática das relações de poder e desenvolvimento. Estereótipos podem se tornar palavras-chave, que indicam o desequilíbrio de poder entre diferentes atores - como trabalhadores e empresas, fabricantes e comerciantes, ou comerciantes e compradores - e que legitimam uma série deles em objetos de esforços para o desenvolvimento (Ribeiro, 2008). Cabe entender que o contexto da inserção desse movimento, ou modelo de gestão organizacional, é caracterizado pelo liberalismo econômico, que tem gerado externalidades predominantemente negativas para o equilíbrio entre elementos essenciais ao desenvolvimento, ou seja, sociedade, economia e meio ambiente. Neste contexto, há a demanda por organizações, ou modelos alternativos de gestão, que tenham princípios balizadores da atuação do indivíduo, consciente da necessidade de senso de justiça e ética (Bolman \& Deal, 2009), que apresentem conexões entre ambiente interno e externo (Ulrich \& Smallwood, 2009) e em conexão com o senso de coletividade (Handy, 2009). Assim, o CJ desponta como uma proposta alternativa para a passagem do atual modelo econômico, marcado pelo capitalismo fragilizado (Handy, 2009), para um modelo sustentável que respeite as demandas de cunho socioambiental relacionadas às organizações e essenciais à manutenção da sustentabilidade.

O CJ, segundo alguns críticos, é caracterizado como um sistema alternativo, ou simplesmente, um reflexo da necessidade de oferta de uma nova gama de produtos éticos, observando o limite da lógica comercial, fortificando e mantendo os laços sociais, de modo a superar as contradições inevitáveis (Gendron et al., 2009). Diferentes pontos de vista entre indivíduos podem vir a comprometer o resultado objetivado: a justiça na relação de troca. Analisar o CJ é uma das alternativas para avaliar aspectos diversos, tal como a relevância das redes sociais para a reconfiguração do modelo econômico (Capra, 2005), sendo esta mais uma alternativa para a perpetuação do sistema econômico (Bisaillon et al, 2005), ou uma proposta alternativa que viabiliza a reconfiguração das trocas internacionais (Gendron et al., 2009).

Portanto, o avanço nessa temática apresenta como potencial de contribuição - seja acadêmica ou prática - a análise de diferentes perspectivas para a compreensão das dinâmicas de poder existentes nas relações de troca internacionais - especialmente por se tratar de uma proposta que tem em seu cerne o princípio de justiça. Paralelamente, há a relevância de buscar conjugar os interesses de mercado e sociedade, focando no estudo das relações de troca e desenvolvimento. No que tange ao interesse específico das organizações, este estudo analisa a existência de contribuição efetiva de uma proposta de gestão organizacional voltada para valores diferenciados daqueles predominantes no mercado, tendo como viés da gestão a base na pluralidade. Cabe questionar a 
validade da proposta, seus aspectos positivos e as deficiências para o aprimoramento da gestão organizacional.

Por se tratar de um tema pouco explorado na gestão - especialmente no contex to brasileiro e de grande relevância, é exigido um esforço superior para a compreensão das diferentes abordagens teóricas e suas implicações na prática. $\mathrm{O}$ estudo do CJ, notadamente das potenciais alternativas para redução de assimetrias de poder, pode vir a contribuir para o entendimento da máxima "manda quem pode, obedece quem tem juízo".

Assim, urge a necessidade de uma abordagem interdisciplinar das atividades de troca internacionais, envolvendo aspectos, tais como políticas de comércio exterior, políticas econômicas e diferenças sociais entre os públicos envolvidos. Sendo as abordagens desenvolvimentistas voltadas para a sustentabilidade amparadas pelo tripé economia, sociedade e meio ambiente, de início já despontam três perspectivas de análise.

\section{A CONVERGÊNCIA ENTRE CJ E PRÁTICAS DE MARKETING SOCIAL}

Tendo em vista a preocupação do CJ para com a sociedade e o meio ambiente, faz-se relevante abordar outro conceito relacionado à geração de bem-estar a ela e aos seus componentes. Este conceito, bastante recente, em especial no Brasil, é o Marketing Social, definido como um meio por intermédio do qual "[...]uma empresa desenvolve ou implementa uma campanha de mudança de comportamento visando a melhorar a saúde, segurança, ambiente e o bem-estar da sociedade" (Kotler \& Lee, 2005, p.114). Mesmo relacionado ao marketing tradicional, o Marketing Social demonstra novas características como objeto de preocupação.

Inicialmente, o Marketing Social foi definido como "[...]a concepção, execução e controle de programas calculados para influenciar a aceitabilidade de ideias sociais, envolvendo considerações de planejamento de produtos, precificação, comunicação, distribuição e pesquisa de marketing" Kotler e Zaltman (1971, p.5). A partir desta definição, surgiu a proposta de compreensão do Marketing Social como "[...] a adaptação de tecnologias de marketing comercial a programas projetados para influenciar o comportamento voluntário de públicos-alvo para melhorar o seu bem-estar pessoal e o da sociedade da qual fazem parte" (Andreasen, 1994, p.110). Tal definição claramente se refere a um comportamento que leva em consideração a sociedade e seu bem-estar.

A expressão "Marketing Social" é utilizada quando uma empresa faz uso, conjuntamente, de ações sociais e atividades de marketing, visando acarretar benefícios para a sociedade, e não tencionando criar vínculos com a marca ou vender mais - como têm feito atualmente diversas organizações (Zenone, 2006). O termo é, eventualmente, usado de forma errônea para se referir apenas ao aspecto da promoção de intervenções com múltiplos componentes ou campanhas que são puramente baseadas em comunicação (McDermott, Stead \& Hastings, 2005). Kotler, Kartajaya e Setiawan (2010, p.146) demonstram concordar com esta observação, ao indicar que "[...] abordar os desafios sociais não deve ser apenas uma ferramenta de relações públicas ou um meio de difundir críticas sobre algum incidente negativo provocado por práticas da empresa". Segundo os autores, é obrigação das empresas atuar como cidadãos corporativos e considerar os problemas sociais em seus modelos de negócios. A extensão abrangida pelo Marketing Social deve focar na melhoria da sociedade em si e nas consequências relacionadas aos aspectos estratégicos do desenvolvimento humano (Wasan e Tripathi, 2015).

Com base nessas definições, percebe-se que o Marketing Social está bastante relacionado à responsabilidade social, definida como a "[...] responsabilidade para com a comunidade e/ou o meio ambiente[...]" (Kotler \& Lee, 2005, p.14), ainda que esta seja uma das várias definições existentes para o termo, considerado ainda um "conceito em formação" (Barreto, Neto \& Tanure, 2013). Empresas de sucesso precisam de uma sociedade vigorosa, no que se refere a aspectos de educação, saúde e oportunidades iguais para gerar uma força de trabalho produtiva (Kotler e Kramer, 2006). Produtos seguros e condições salubres de trabalho não só reduzem os riscos de acidentes como também atraem mais clientes. A mesma observação é válida para uma utilização eficiente dos 
recursos naturais, tais como terra e água, o que conduz a uma maior produtividade dos negócios. Padrões de conduta e regulamentos sobre comportamentos adequados também protegem consumidores e empresas de exploração indevida. Aqui, nota-se a necessidade de aplicação de princípios específicos do CJ, uma vez que suas ideias e visões - além dos próprios princípios mencionados - são de extrema relevância para o consumo ético (Langen \& Adenaeuer, 2013). O $\mathrm{CJ}$, implementado em determinadas práticas que lhe são peculiares, representa o apoio de uma empresa a causas sociais (Cabrera e Williams, 2012) - assim como observado em práticas de Marketing Social.

Nas grandes empresas, em especial nos tempos atuais, as práticas de Marketing Social vêm ganhando força com a crescente demanda da sociedade para que empresas e organizações se engajem em práticas socialmente responsáveis. O Marketing Social tem como finalidade o desenvolvimento de programas para encorajar (ou não) a aceitação de ideias ou comportamentos sociais (Vázquez, 2006). Assim, seus objetivos podem ser resumidos em: proporcionar informação, estimular ações benéficas para a sociedade, modificar comportamentos nocivos e transformar os valores da sociedade. Para as grandes empresas e corporações, o Marketing Social se mostra uma alternativa de interação com o ambiente que as cerca, incluindo os consumidores e a sociedade. $\mathrm{O}$ diferencial é o foco na mudança de comportamento de consumo, que distingue o Marketing Social das meras promoções de uma causa, cujo foco é no apoio à sensibilização, levantamento de fundos ou recrutamento de voluntários para uma determinada ação (Kotler e Lee, 2008).

Em suma, uma sociedade sustentavel favorece a expansão dos negócios na medida em que as necessidades são satisfeitas e as aspirações se desenvolvem. Qualquer empresa que persiga seus fins em detrimento do bem-estar da sociedade em que atua alcançará, no máximo, um êxito aparente ou efêmero. Assim como as empresas precisam de uma sociedade saudável, esta igualmente precisa de empresas que atuem de modo correto, e tanto de forma social quanto comercialmente justa. Contudo, dificilmente programas sociais podem ser igualados aos recursos do setor empresarial na geração de riqueza, empregos e evolução da qualidade de vida no longo prazo. Desta forma, nota-se a importância de outro conceito importante e associado ao Marketing Social, que é a Responsabilidade Social Empresarial, definida pelo Instituto Ethos (2009) como a forma de gestão que se define pela relação ética e transparente da empresa com todos os públicos com os quais se relaciona e pelo estabelecimento de metas empresariais compatíveis com o desenvolvimento sustentável da sociedade, preservando recursos ambientais e culturais para gerações futuras, respeitando a diversidade, além de promover a redução das desigualdades sociais. Para Zenone (2006), a Responsabilidade Social Empresarial pode ser definida como o compromisso que uma empresa deve assumir com a sociedade em que atua.

A Responsabilidade Social Empresarial, ou Corporativa, transpôs dois estágios (Porter, 2007). O primeiro, foi o da reação a pressões políticas - neste momento, as empresas se viram forçadas a responder por questões que não acreditavam ser de sua responsabilidade. Neste estágio, as ações realizadas não foram voluntárias, mas sim motivadas por críticas que geravam publicidade negativa. O segundo estágio teve início há não muito tempo e ainda é praticado por diversas organizações. Nele, as empresas perceberam que a Responsabilidade Social poderia servir como um instrumento para a construção de uma imagem. Foi quando as ações passaram a se suceder a partir do interior das organizações.

Muitas empresas integram ações de Responsabilidade Social aos seus negócios e à sua atuação com o objetivo de obter benefícios. Para isto, incluem-nas em suas campanhas de marketing, associando-as à sua marca e aos seus produtos (ou serviços). Desta forma, fortalecem sua marca, garantem uma boa reputação, conquistam novos mercados, além de atrair e fidelizar consumidores (Oliveira, 2008). Para que uma empresa consiga obter resultados satisfatórios por meio da Responsabilidade Social, é importante incluí-la na sua estratégia central. O conceito de sustentabilidade é visto como uma oportunidade de negócio (Porter, 2007), mas sem que as necessidades dos consumidores e da sociedade, além daquelas das empresas, sejam esquecidas ou desprezadas.

Revista de Gestão Social e Ambiental - RGSA, São Paulo, v. 9, n. 3, p. 63-79, set./dez., 2015. 
Avaliando, em âmbito geral, a compreensão do Marketing Social e seu benefício para a sociedade podem ser percebidos na comparação com o marketing convencional, cujo foco recai em produzir e fornecer aos clientes aquilo que desejam, gerando lucro para a empresa. Na definição de Boone e Kurtz (1999, p.9), marketing é “[...]o processo de planejar e executar a concepção, precificação, promoção e distribuição de ideias, bens, serviços, organizações e eventos para criar e manter relacionamentos que satisfaçam objetivos individuais e organizacionais". Percebe-se que o foco situa-se nos objetivos individuais (ou seja, dos consumidores) e organizacionais (das organizações e empresas). O Marketing Social, por sua vez, dá ênfase ao que é suscitado para a coletividade, em termos de bem-estar e pela alteração de comportamentos que gerarão benefícios à sociedade como um todo (Andreasen, 1994). Na orientação do Marketing Societal (ou Societário), muitas vezes confundido com o Marketing Social, pode-se notar que as empresas desejam obter lucro, enquanto os clientes esperam ter seus desejos e necessidades satisfeitos, mas isto deve se dar sem dano ao ambiente compartilhado por ambos e visando ao bem-estar destes no longo prazo, como no esquema mostrado na Figura 2. Na abordagem do Marketing Societal, aparece um "novo" ator - a sociedade, que é afetada pelo contato entre clientes e empresas e necessita de que seja gerado bem-estar para si quando da interação entre estes.

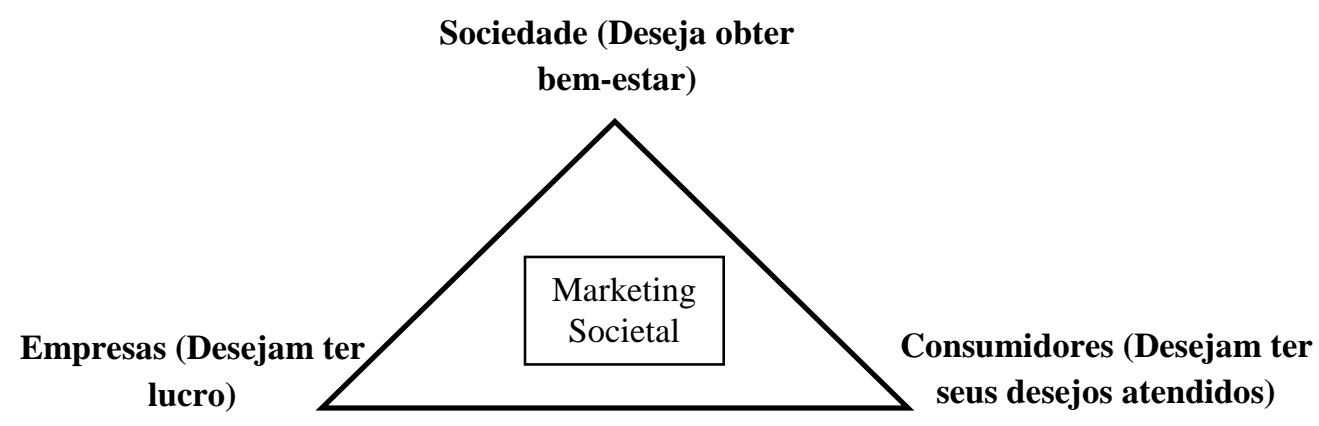

Figura 2 - Atores do Marketing Societal

Fonte: Adaptado de Kotler (1997)

Como exposto anteriormente, o CJ foca no tripé economia, sociedade e meio ambiente. Analisando o outro tripé, exposto na Figura 2, percebe-se claramente a interseção entre o Marketing Social e o CJ, que é exatamente a sociedade. A economia relaciona-se às empresas e à sua atuação, e o meio ambiente englobaria também os consumidores, que nele vivem e participam de sua manutenção.

Assim, as atividades do Marketing Social visam influenciar o comportamento do público a quem se destinam as ações sociais em questão, conhecido como os adotantes-alvo de tais ações. Tal influência pode ocorrer de formas diversas, mas o importante é observar que se busca um impacto positivo na sociedade e naqueles que dela fazem parte. Há uma relação essencial entre o marketing e a responsabilidade social, mencionando que "[...] de um modo geral, a responsabilidade social demanda que os profissionais de marketing aceitem a obrigação de dar o mesmo peso ao lucro, à satisfação do consumidor e ao bem-estar social ao avaliar o desempenho de uma empresa" (Boone e Kurtz, 1999, p.105). Neste aspecto, o Marketing Social se relaciona com o CJ, tendo em vista que este estabelece a necessidade da existência não só de preços justos, adequados e convenientes, mas de padrões sociais e ambientais equilibrados, visando a uma sociedade com maior bem-estar, além de mudança de consciência e comportamentos de cidadãos e consumidores - ao implementar e estimular a consciência cidadã, solidária e ética nas relações de troca.

Destarte, Witkowski (2005) aponta que, mesmo diante do fato de muitos dos apoiadores do CJ serem críticos das práticas tradicionais de marketing, caso exista a intenção de que mais produtores sejam beneficiados, torna-se necessário ganhar escala via a criação de marcas mais 
fortes e da gestão profissional das mesmas, o incremento dos sistemas de distribuição e a criação de parcerias com grandes empresas. Há, portanto, que se notar, ainda, a necessidade de buscar conjugar os interesses de mercado e sociedade, que no CJ focam nas relações de troca e desenvolvimento, como já mencionado, e no Marketing Social focam na geração de bem-estar para a sociedade, sem prejudicar o lucro das organizações e a satisfação dos clientes e consumidores.

\section{METODOLOGIA}

A pesquisa realizada é classificada como exploratória, uma vez que busca familiaridade com um assunto ainda pouco explorado, bem como maior conhecimento dos fenômenos abordados. A natureza é qualitativa, sendo o método utilizado a análise de discurso (AD), que aponta ser o receptor da mensagem um dos pontos-chave da $\mathrm{AD}$, a qual deve ter como foco a interpretação daquilo que o emissor transmite em suas palavras (Vergara, 2008).

Foram analisadas empresas de grande porte, multinacionais, que sugerem atuar há, no mínimo, cinco anos com práticas de CJ e também de Marketing Social. Foram obtidas notícias da natureza buscada sobre as empresas Cadbury (8 notícias), Walmart (15), Nestlé (17), Unilever (13), eBay (9) e Starbucks (11).

Com o uso do critério de acessibilidade às informações, foram selecionadas seis empresas dessa natureza, todas bastante conhecidas em âmbito mundial (Figura 3). Com base em informações e dados disponibilizados na rede mundial de computadores sobre elas, coletados com o uso de ferramentas específicas para tal propósito - como Google Alerts e TalkWalker principalmente, direcionados à obtenção de notícias e informações dirigidas ao público consumidor - por meio de websites principalmente, ainda que estes englobassem notícias também veiculadas na mídia tradicional, foram analisados os conteúdos referentes às práticas de $\mathrm{CJ}$, por um período de 14 meses.

Como mencionado por Caregnato \& Mutti (2006, p.681), “o enunciado não diz tudo", ou seja, é necessário interpretar o que é apresentado nas notícias veiculadas, em particular no caso presente, em que empresas de grande porte (mainstream) se apresentam como utilizadoras do CJ e, eventualmente, se mostram adeptas de práticas de Marketing Social. O material obtido foi esquadrinhado por meio da AD, seguindo o roteiro proposto por Vergara (2008). Logo após a definição da fonte de dados (notícias sobre as empresas, dirigidas ao consumidor, por vezes veiculadas pelas próprias organizações, no presente caso), foram organizados os dados e indicados os aspectos relevantes, como linguagem utilizada, foco do discurso e o que nele se enfatiza. A seguir, avaliaram-se os discursos em si.

Tendo sido obtidos os dados, estes foram tratados de maneira a fornecer informações sobre os procedimentos de grandes empresas, relacionados ao CJ e ao Marketing Social. Empresas de médio e pequeno portes foram desconsideradas por não se adequarem ao universo proposto, assim como práticas não relacionadas aos assuntos supracitados.

\section{RESULTADOS E DISCUSSÃO}

Dentre os achados, nota-se que o discurso das empresas recai basicamente sobre os produtos/serviços que oferecem, alinhado com a ótica do CJ - e direta ou indiretamente com o Marketing Social - e com as instituições em si, que desejam transmitir a ideia de respeitadoras da sociedade, como mostrado nos dizeres a seguir.

Sempre trabalhamos para comprar nosso café de forma que respeitasse as pessoas e os locais que o produzem. É simplesmente o que acreditamos estar certo (Starbucks, em seu website). Para a Unilever, é fundamental que toda sua cadeia de valor pense a sustentabilidade de maneira estratégica e transversal ao negócio. Acreditamos que, ao fomentar uma atuação sustentável, estamos promovendo uma mudança na maneira como fazer negócio e, consequentemente, na sociedade como um todo (Unilever, em seu website). 
O produto [café solúvel com o rótulo do $\mathrm{CJ}$ ] se chama em inglês Partner's Blend e o rótulo diz: "Café que ajuda aos agricultores, a suas comunidades e ao meio ambiente" (Agência EFE, sobre a Nestlé, out/2005).

Nota-se que as empresas, em sua grande maioria, se colocam como preocupadas com o meio ambiente, com a sociedade e (indiretamente) com a influência supostamente positiva perante aqueles que as rodeiam, concordando com o princípio de bem-estar em longo prazo, do Marketing Social.

A compra socialmente responsável está crescendo e se aperfeiçoando graças ao site WorldofGood.com, afirmou em um comunicado Lorrie Norrington, presidente do eBay Marketplaces (referência ao website lançado pelo eBay como uma alternativa para os "clientes ecológicos e preocupados com um tratamento mais ético dos trabalhadores")

(...) [o fato de a Cadbury ter quadruplicado o volume de cacau produzido sob a ótica do CJ em Gana] representa "um novo compromisso de seus meios de vida sustentáveis" (Sarah LewisHammond, jornalista ambiental).

Dadas as constatações, por parte das multinacionais líderes do mercado de trocas internacionais, de que a demanda consumidora por produtos provenientes de empresas social e ambientalmente responsáveis gradativamente se amplia, o CJ veio a ser inserido nas práticas das denominadas mainstream. $\mathrm{O}$ fato de destaque é que, nessas organizações, o investimento em reputação social deve ser complementado por linhas de produto nas quais a empresa é demandada, de alguma forma, pelos seus grupos de interesse, dado que empresas socialmente orientadas podem aumentar sua reputação em mercados de produtos com alto valor simbólico (Castaldo et al., 2009), como exposto a seguir:

Criamos o Worldofgood.com para habilitar compradores a adquirir produtos socialmente responsáveis com confiança (Robert Chatwani, gerente geral do WorldofGood.com, do Ebay)

Medidas adotadas [para produção de café] que avaliam as condições de trabalho seguras, justas e humanas. Elas incluem a proteção dos direitos dos trabalhadores e o fornecimento de condições de vida adequadas. (diretrizes para compra de café do Starbucks, denominadas C.A.F.E - Coffee and Farmer Equity).

Estamos orgulhosos de ser parte desta iniciativa, que se encaixa na nossa abordagem de longo prazo para garantir o bem-estar dos fazendeiros e propiciar benefícios sociais para os agricultores. (Jean-Marc Duvoisin, CEO da Nestlé Nespresso).

[A Unilever lança] novidades, como o sorvete premium Ben \& Jerry's, que possui uma pegada sustentável ao adotar as práticas do CJ, que privilegiam fornecedores de menor porte (Revista IstoÉ Dinheiro, 2015).

Apesar da importância do uso de CJ e Marketing Social pelas organizações estudadas, obtiveram-se algumas críticas relacionadas, em especial, ao montante de produtos de CJ em relação ao total despendido pelas empresas. Tais críticas abarcam o mencionado por Gendron et al. (2009), sobre a lógica comercial, ainda existente e influenciadora das ações de certas empresas, embora sustentando laços comerciais.

Unilever, Nestlé e P\&G passaram a comprar produtos do CJ, embora, verdade seja dita, em escala minúscula diante do total de seus negócios. (...) $\mathrm{O}$ casamento de interesses entre grandes corporações e pequenos produtores até recentemente indefesos tem um quê perturbador (....). Os grandões delegaram o CJ aos seus departamentos de marketing. Então, em vez de pagarem a todos os agricultores um salário digno, porque isso é ético e bom para os negócios a (sic) longo prazo, limitam o CJ a apenas mais uma opção no seu cardápio. (Regina Scharf, Revista Página 22, 2008)

Starbucks só vende cerca de 1 a $2 \%$ de seus grãos certificados pelo Comércio Justo (Revista Íconos, artigo de Gavin Fridell: CJ, neoliberalismo y desarollo rural, 2005).

Um dos fatores distintivos para o crescimento do movimento de CJ e sua inserção no mainstream é destacado por Hira e Ferrie (2006), argumentando que, atualmente, o suprimento é superior à demanda existente nos meios utilizados para comércio pelas redes, dado que estas têm um acesso limitado. Em resposta, houve um movimento de liberação dos produtos certificados, de 
modo a introduzi-los nos canais de distribuição do mainstream. Da mesma forma, as grandes empresas têm aceitado o CJ como um nicho crescente de mercado e uma oportunidade de benefícios para a reputação. O diferencial dos produtos social e ambientalmente corretos é que, ao caracterizar o produto em um senso de justiça na luta anti-hegemônica, é criado um fetiche em torno do processo de compra, pois as pessoas não entendem o bem como commodity, mas como um bem com valor agregado (Hudson \& Hudson, 2003).

Dentre algumas manifestações das grandes corporações multinacionais, estão as elencadas na figura 3.

\begin{tabular}{|c|c|}
\hline Empresa & Ação \\
\hline Starbucks & Aumento da compra de café certificado. \\
\hline Cadbury & Chocolate Cadbury Dairy Milk será totalmente produzido com cacau certificado. \\
\hline Unilever & Busca pela certificação do chá em sachê da marca Lipton. \\
\hline Ebay & $\begin{array}{l}\text { Criação de um portal de venda de produtos numa lógica de CJ e que impacte favoravelmente a } \\
\text { sociedade. }\end{array}$ \\
\hline Nestlé & Comprometeu-se a adquirir cacau e açúcar certificado em CJ, no longo prazo. \\
\hline WalMart & $\begin{array}{l}\text { Maior importador de café certificado do Brasil, lançou seis novos cafés sob a marca (exclusive) } \\
\text { Sam's Choice, incluindo os grãos Orgânicos, Certificação de CJ e Certificação da Aliança da } \\
\text { Floresta Tropical. }\end{array}$ \\
\hline
\end{tabular}

Figura 3 - O comércio justo nas grandes empresas - manifestações perceptíveis

Fonte: Adaptado de Fernandes (2009), Público (2009), Scharf (2008), Godoy (2009), Fairtrade Foundation (2009),

Fator (2009), Sobral (2009).

Mesmo diante de tais esforços cabe, no entanto, destacar aspectos relativos tanto à relevância do consumidor como à participação dos produtores no movimento.

Low e Davenport (2006) constataram que desde o princípio de sua inserção no mainstream, o conceito foi embebido da ideia de participar de um programa de ação transformadora, da mesma forma que é relativo ao consumo de um produto, sem necessariamente "comprar a mensagem". Neste contexto, o movimento de mudança é dependente da ação e demanda do consumidor, e o modelo de mercado não necessariamente desafiado, como ressaltam os autores.

[Worldofgood.com (do Ebay) é] dedicado a construir experiências éticas de consumo, por intermédio de seu profundo conhecimento da cadeia de suprimentos ética global a parceiros varejistas do mainstream. (Brewer-Hay, 2008).

O CJ pode ter começado baseado em um nicho ético, mas os tempos atuais testemunharam sua crescente transformação no mainstream. Nada tipifica mais tal deslocamento do que a principal marca de chocolate do Reino Unido [isto é, a Cadbury] buscar a certificação [de CJ] (Forum for the Future, 2012).

Lyon (2006), por sua vez, aponta que a construção política, por intermédio do CJ, é somente parcialmente possível, pois os produtores não participam de forma igual nas redes e têm pouca força na construção da agenda internacional de Administração. Entretanto, essas fragilidades não necessariamente afetam o potencial transformativo do CJ, tomado como veículo para a transformação da igualdade econômica e justiça social na arena internacional.

Contudo, chama a atenção a afirmação do diretor de e-commerce da Walmart Brasil (apud Olivon, 2010) de que "[o fato da rede (...) oferecer produtos desenvolvidos por comunidades brasileiras] não é filantropia; todas as partes vão ganhar seu dinheiro e vai gerar vantagem competitiva pra gente[...]", por esta ir aparentemente contra os argumentos mencionados de Boone e Kurtz (1999, p.105), referentes a dar o mesmo peso ao lucro, à satisfação do consumidor e ao bem-estar social. Esta afirmação também aparentemente contradiz Zenone (2006), que, como mencionado, afirma que no Marketing Social o foco das ações sociais não deve ser aumentar vendas ou criar vínculos com a marca. 
Não obstante, observa-se que os resultados das ações modificadoras propostas apresentam resultados parciais, tanto em termos de mudança de comportamentos de consumo quanto na alteração das práticas de redes produtoras. Contudo, o diferencial de gerar impactos positivos em termos sociais e ambientais supera as práticas convencionais de gestão. Desta forma, em termos das práticas de Marketing Social, cabe resgatar que um programa deve conter alguns elementos - sendo estes a orientação ao consumidor, a mudança, ao planejamento de longo prazo e foco além do consumidor individual - para que seja bem-sucedido, conforme destacado por MacFayden, Stead e Hastings (2003). Tais elementos devem demonstrar equilíbrio entre si e favorecer a obtenção de bem-estar social no longo prazo, como se observa nos comentários a seguir, a respeito de cada um.

- Orientação ao consumidor: É um elemento-chave observado em qualquer forma de marketing. No Marketing Social, o consumidor é visto como um participante ativo do processo de mudança de comportamento, e o profissional de Marketing Social busca a construção de um relacionamento com os consumidores (ou adotantes-alvo), cujos feedbacks, participação e avaliação são de grande relevância em todos os estágios do desenvolvimento do programa. Uma mostra da busca desse relacionamento é percebida a seguir:

Sam's Club apresentou sua marca própria de café certificado de CJ em 2009. Desde então, compramos mais de 43.000.000 libras de café com certificação de Comércio Justo e entregamos mais de US\$ 6 milhões em remuneração às comunidades agrícolas, valores que têm sido usados em diversos projetos, tais como mitigação de pragas, empoderamento das mulheres, serviços de saúde, melhorias habitacionais e muito mais. (Jeff Seyfarth, comprador sênior do Sam's Club, clube de compras do grupo WalMart, 2015)

Lipton está trabalhando para garantir que todo o chá Lipton seja produzido em propriedades certificadas pela Rainforest Alliance. Por meio desses programas, a Unilever já ajudou 800.000 pequenos agricultores a conseguirem acesso a apoio e treinamento (site Futuro Melhor, da Unilever, 2014)

- Mudança/Câmbio: Trata-se de uma troca de recursos ou valores entre duas partes ou mais, com a expectativa de algum benefício. A motivação de se envolver em uma mudança é a satisfação de necessidades ou desejos, como quando se "trocam" votos pela expectativa de menos impostos, bens por dinheiro, impostos por segurança e saúde, entre outros exemplos. No caso do Marketing Social propriamente dito, o foco recai no comportamento voluntário, ou seja, oferecer algo que o indivíduo realmente deseje para obter sua participação espontânea. Um exemplo simples se refere a uma campanha de uso de preservativos por jovens a fim de prevenir doenças sexualmente transmissíveis (DST). Se os jovens têm maior preocupação com uma gravidez indesejada do que com as DST, então os benefícios contraceptivos dos preservativos devem ser ressaltados em vez de (ou tanto quanto) os de prevenir DST. No caso das empresas estudadas, destaca-se o seguinte exemplo:

A Nestlé está estabelecendo projetos-piloto na Costa do Marfim [maior produtor mundial de cacau, com quem uma boa relação é extremamente útil] e se compromete a comprar cada vez mais grãos [de cacau] com certificação UTZ [programa global de certificação de produção agrícola responsável] nos próximos anos (NestleCocoaPlan, 2013).

- Planejamento de longo prazo: Assim como no marketing tradicional, a continuidade dos programas é extremamente relevante; não se deve pensar em ações pontuais, mas sim em manter na mente das pessoas os comportamentos que geram benefícios no longo prazo, o que virá a beneficiar uma quantidade cada vez maior de indivíduos. O foco deve ser estratégico, e não tático, o que explica a preocupação com o planejamento de marketing ao se tratar do Marketing Social. O exemplo da Starbucks, a seguir, ilustra tal situação:

Este compromisso de longo prazo vai dar aos nossos clientes a garantia de que o café comprado no Starbucks (...) é a um preço que permitirá a sustentabilidade para aquelas pessoas que mais necessitam (Howard Schultz, CEO da Starbucks, 2009.)

- Foco além do consumidor individual: O Marketing Social não visa influenciar apenas o comportamento de indivíduos, mas também de empresas, grupos e sociedades. Assim, é possível 
influenciar mudanças nos curto e longo prazos, bem como nas dimensões micro, macro e de grupo (Levy \& Zaltman, 1975). No curto prazo, haveria as mudanças de comportamento (dimensão micro), de normas e regras administrativas (dimensão de grupo) e de políticas (dimensão macro). No longo prazo, as mudanças seriam de estilo de vida (micro), organizacionais (de grupo) e socioculturais (macro), como observado em relação ao Walmart:

(...) a empresa parece mesmo decidida a mudar essa visão [antiga, de despreocupação com empregados e outras práticas] em cima de sua imagem institucional, ao apostar em práticas sustentáveis (site EcoDesenvolvimento.org, 2008)

Tendo em vista tais elementos, e as ações das empresas citadas na figura 4, notam-se diversas atuações e características homogêneas, e mesmo similares, em muitas delas, o que corrobora a atuação socialmente responsável em termos do Marketing Social. Percebe-se especificamente, em âmbito geral, que a Starbucks planeja a melhoria da qualidade daquilo que é consumido por todos os seus clientes, o que demonstra forte orientação ao consumidor e planejamento de longo prazo. O mesmo pode ser dito da atuação da Unilever e da Cadbury, focando no bem-estar social no longo prazo, o que representa um planejamento em termos estratégicos, e não meramente táticos. Analisando a ação do Ebay, percebe-se a tentativa de alteração de um comportamento, a fim de criar um impacto positivo em termos sociais, fazendo uso do CJ e atuando de forma socialmente responsável, em consonância com o Marketing Social. A Nestlé faz uso do CJ como ferramenta de Marketing Social, usando um produto líder de vendas e relacionado à marca da fabricante, o que atrai a atenção para a atuação eticamente correta da empresa. Finalmente, WalMart demonstra perceber que os clientes dão valor às iniciativas que geram impactos positivos à sociedade em que empresas e clientes se inserem. No caso, ambos obtêm o que desejam e a sociedade não é prejudicada; ao contrário, no longo prazo gera-se bem-estar e os recursos utilizados pelas empresas são vistos como investimentos, e não como gastos ou dispêndios desnecessários, e acabam se revertendo em benefícios para todos os que fazem parte de uma mesma sociedade.

\section{CONSIDERAÇÕES FINAIS}

A inserção de práticas de CJ e Marketing Social no mercado, especialmente nas grandes empresas, envolve a mudança de valores, formas de atuação e gestão organizacional. Nesta perspectiva, há uma nova abordagem acerca da cultura e práticas organizacionais, no que concerne às relações de troca, ao desenvolvimento de diferentes certificações, à atenção à pluralidade e aos demais aspectos até então relegados ao segundo plano - seja pelo meio acadêmico, pelas empresas, pela sociedade ou por governos.

Desponta a necessidade de que a sociedade em geral se torne mais receptiva e interessada por propostas plurais e em prol da sustentabilidade. Contudo, vale ressaltar que ainda predomina a noção da proposta de justiça nas relações de troca como utópica, ou de que estudos voltados para questões sociais ou ambientais são de menor importância para muitas vertentes do estudo da gestão - considerados subtemas ou "temas de pouca relevância", especialmente para a realidade empresarial.

O CJ se coloca como uma alternativa para a redução de assimetrias de poder e para o desenvolvimento territorial sustentável, que demanda aprimoramento da compreensão acerca das dinâmicas existentes, bem como das fragilidades e contribuições. Há empresas que percebem o CJ como uma prática socialmente responsável merecedora de destaque, resultando em uma melhor receptividade das adeptas de tal prática, nos tempos atuais, pela coletividade. Tal postura se alinha ao cerne do Marketing Social, com sua busca pelo bem-estar social por meio da alteração de comportamentos que possam gerar danos potenciais aos partícipes do mercado e da sociedade.

Paralelamente, observa-se que para que a sociedade seja considerada nas relações entre consumidores e empresas de qualquer natureza, é necessário que haja não só respeito entre ambos, mas, para com a comunidade que os envolve. Neste contexto, as práticas comerciais podem ser direcionadas para o bem-estar social, ocasionado no aprimoramento da relação entre consumidor e

Revista de Gestão Social e Ambiental - RGSA, São Paulo, v. 9, n. 3, p. 63-79, set./dez., 2015. 
empresa, assim como na justiça do comércio. Consequentemente, desenvolvem-se pontos relevantes para o fortalecimento de uma atuação socialmente responsável, tanto de consumidores quanto de empresas e produtores, gerando benefícios à sociedade como um todo. Aspectos relevantes a serem considerados englobam orientação ao consumidor, mudança, planejamento de longo prazo e foco além do consumidor individual.

No discurso das empresas analisadas, verificou-se preocupação constante em se realizarem ações relacionadas ao CJ e às práticas de Marketing Social, e também em divulgar o trabalho concretizado. Nota-se que os achados da pesquisa corroboram, em grande parte, o que se observa na literatura sobre os temas (Gendron et al, 2009; MacFayden, Stead e Hastings, 2003; Witkowski, 2005) -, abordando os conceitos presentes no discurso das mainstream das grandes empresas e revelando os conceitos de CJ e Marketing Social aqui expostos. Paralelamente, destaca-se que, mesmo que tais condutas ofereçam potencial de valorização das marcas, há riscos envolvidos no processo de comunicação - como de eventualmente haver má compreensão, acarretando na percepção de que o discurso difere da prática, ainda que a empresa seja espontânea e ética em sua conduta.

Diversos são os desafios envolvidos no aprimoramento das temáticas envolvidas. Para pesquisas futuras, recomenda-se uma análise das práticas comerciais e existentes no mercado, em termos de produção e consumo, e o quanto a sociedade as considera adequadas ao momento atual.

\section{REFERÊNCIAS}

Adenauer, N.L.L. (2013) Where does the fair trade price premium go? Confronting consumers' request with reality. Social Enterprise Journal, 9(3), 293-314.

Andreasen, A. R. (1994) Social marketing: its definition and domain. Journal of Public Policy \& Marketing, 13 (1), 108-114, Spring.

Barreto, L. G. M., Neto, A. C., \& Tanure, B. (2013) Liderança globalmente responsável: a percepção dos executivos sobre as práticas nas organizações brasileiras. RGSA-Revista de Gestão Social e Ambiental, São Paulo, 7 (1), 3-18, jan./abr.

Bisaillon, V., Gendron, C., \& Turcotte, M. (2005) Commerce équitable comme vecteur de développement durable ? In: Nouvelles pratiques sociales, 18 (1), 73-89, Automne.

Bolman, L. G., \& Deal, T. E. (2009) Reframing ethics, spirit and soul. In: Hesselbein, Frances; Goldsmith, Marshall (coords.). The organization of the future: visions, strategies and insights on managing a new era. San Francisco: Jossey-Bass.

Boone, L.E., \& Kurtz, D.L. (1999) Contemporary marketing. Orlando: The Dryden Press. Brewer-Hay, R. (1998). Introducing Worldofgood.com. Recuperado em: 10 jul.2014, de https://www.ebayinc.com/stories/news/introducing-worldofgoodcom/.

Bucolo, E.(2003) Le commerce équitable. Hermès, La Revue, 36, 109-118.

Cabrera, S.A., \& Williams, C. L.(2012) Consuming for the social good: marketing, consumer citizenship, and the possibilities of ethical consumption. Critical Sociology, (40)3, 348-367.

Capra, F. (2005). As conexões ocultas: ciência para uma vida sustentável. São Paulo: Cultrix. Caregnato, R.C.A., \& Mutti, R. (2006) Pesquisa qualitativa: análise de discurso versus análise de conteúdo. Texto \& Contexto Enfermagem, 15(4), 679-684, Out-Dez.

Castaldo, S.,et al. (2009) The missing link between corporate social responsability and consumer trust: the case of Fair Trade products. Journal of Business Ethics, 84, 1-15.

Edward, P., \& Tallontire, A. (2009) Business and development: towards re-politicisation. Journal of International Development, 21, 819-833. 
Fairtrade Foundation (2009) Kit Kat gives cocoa farmers in Côte d'Ivoire a break. Recuperado em: 8 dez.2014, de: www.fairtrade.org.uk/press_office/press_releases_and_statements/december_2009/ kit_kat_gives_cocoa_farmers_in_cte_divoire_a_break.aspx.

Fator. (2009) Cadbury inicia processo de certificação de comércio sustentável da organização Fairtrade (05 mar. 2009). Recuperado em: 11 nov.2014, de: http://www.revistafator.com.br/ver_noticia.php?not=69376 .

Fernandes, N.(2009) Não é mais só conversa de ONG. Revista Exame, ed.941, 16 abr. 2009. Recuperado em: 11 nov.2014, de: http://portalexame.abril.com.br/revista/exame/edicoes/0941/gestao/nao-mais-so-conversa-ong449541.html.

Flo - Fair Trade Labelling Organizations International.(2008) An inspiration for chance. Recuperado em: 18 out.2014, de: www.fairtrade.net/fileadmin/user_upload/content/FLO_AR2007_low_res.pdf.

Forum for the Future. (jun.2012) Fairtrade gets a boost from Cadbury Dairy Milk. Recuperado em: 3 jul.2013, de: https://www.forumforthefuture.org/greenfutures/articles/fairtrade-gets-boostcadbury-dairy-milk.

Francés, D.S., Gardó, T.F., Moreno, F.J.A., \& Granizo, M.G. (2012) La motivación de compra de productos de comercio justo: propuesta de un índice de medición por diferencias sociodemográficas. Bogotá. Cuadernos de Administración, 25 (45), 63-85, jul./dec.

Gendron, C., Bisaillon, V., \& Rance., A.I.O. (2009) The institutionalization of fair trade: more than just a degraded form of social action. Journal of Business Ethics, 86, 63-79.

Godoy, J.(2009) World: more questions about fair trade practices. Recuperado em: 1 dez.2014, de: http://ipsnews.net/news.asp?idnews=44863.

Handy, C.(2009) Revisiting the concept of the corporation. In: Hesselbein, F., Goldsmith, M. (coords.). The organization of the future: visions, strategies and insights on managing a new era. San Francisco: Jossey-Bass.

Hayes, M. G. (2008) Fighting the tide: alternative trade organizations in the era of global free trade - A comment. World Development, 36 (12), 2953-2961.

Hira, A., \& Ferrie, J. (2006) Fair trade: three hey challenges for reaching the mainstream. Journal of business ethics, 63, 107-118.

Hudson, I., \& Hudson, M. (2003) Removing the veil? Commodity fetishism, Fair Trade and the environment. Organization and Environment, 16 (4), 413-430.

Instituto Ethos. (2009). Recuperado em: 5 set.2014, de: http://www.ethos.org.br.

Kotler, P. (1997) Marketing management: analysis, planning, implementation, and control. (9th.ed.) New Jersey: Prentice Hall.

Kotler, P., Kartajaya, H., \& Setiawan, I. (2010) Marketing 3.0: as forças que estão definindo o novo marketing centrado no ser humano. Rio de Janeiro: Elsevier.

Kotler, P., \& Kramer, M.R. (2006) Strategy and society: the link between competitive advantage and corporate social responsibility. Harvard Business Review,1-14, Dec.

Kotler, P., \& Lee, N. (2005) Corporate social responsibility: doing the most good for you company and your cause. New Jersey: John Wiley \& Sons, Inc.

Kotler, P, \& Lee, N. (2008) Social marketing: influencing behaviors for good. T.Oaks: Sage.

Kotler, P., \& Roberto, E.L. (1992) Marketing social: estratégias para alterar o comportamento do 
público. Rio de Janeiro: Campus.

Kotler, P., \& Zaltman, G. (1971) Social marketing: an approach to planned social change. Journal of Marketing, 35, 3-12.

Langen, N., \& Adenaeuer, L. (2013) Where does the fair trade price premium go? Confronting consumers' request with reality. Social Enterprise Journal, 9 (3), 293-314.

Levy, S.J., \& Zaltman, G. (1975) Marketing, society and conflict. New Jersey: Prentice Hall.

Lyon, S. (2006) Evaluating fair trade consumption: politics, defetishization and producer participation. International Journal of Consumer Studies, 30 (5), 452-464.

Low, W, \& Davenport, E. (2006) Mainstreaming fair trade: adoption, assimilation, apropriation. Journal of Strategic Marketing, 14, 315-327.

Macfayden, L., Stead, M., \& Hastings, G. (2003) The marketing book. Baker, John (ed.). Oxford: Elsevier.

Mcdermott, L., Stead, M., \& Hastings, G. (2005) What is and what is not social marketing: the challenge of reviewing the evidence. Journal of marketing Management, 21, 545-553.

Oliveira, J. A. P. (2008) Empresas na sociedade: sustentabilidade e responsabilidade social. Rio de Janeiro: Elsevier.

Olivon, B. (2010) Walmart lança parceria para comércio justo na internet. Exame.com. Recuperado em: 11 set.2013, de: http://exame.abril.com.br/negocios/noticias/walmart-lanca-parceria-comerciojusto-internet-565674, jun.

Porter, M.(2007) Parem de gastar tanto dinheiro. Guia Exame 2007- Sustentabilidade, São Paulo, 1, 86-89,dez.

Público. (2009) eBay adere ao comércio justo. Recuperado em: 17 dez.2014, de: www.publico.clix.pt/Media/ebay-adere-ao-comercio-justo_1341476.

Raynolds, L. T. (2009) Mainstreaming fair trade coffee: from partnership to traceability. World Development, 37 (6), 1083-1093.

Renard, M. (2003) Fair trade: quality, market and conventions. Journal of Rural Studies, 19 (1), 87 96.

Renard, M. (2005) Quality certification, regulation and power in fair trade. Journal of Rural Studies, 21 (4), 419-431.

Scharf, R. (2008) Comércio Justo S.A. Página 22, 21. Centro de Estudos em Sustentabilidade da EAESP - FGV. 50-51, Jul.

Schmitt, V. G. H. (2011) As dimensões da sustentabilidade nas relações de poder: o comércio justo no setor alimentício brasileiro (Tese de doutorado, Ebape/FGV, 2011). Rio de Janeiro, Brasil.

Schneider, J.(2012) Relatório pesquisa mundial de comércio justo: parte2. Brasília: Sebrae

Sobral, L. (2009) Entenda como funciona o comércio justo. Época Negócios. ed. 25. Recuperado em: 12 dez.2014, de: http://epocanegocios.globo.com/Revista/Common/0,,EMI64038-16381,00ENTENDA+COMO+FUNCIONA+O+COMERCIO+JUSTO.html.

Stiglitz, J.E., \& Charlton, A. (2005) Fair trade for all: how trade can promote development. New York: Oxford University Press.

Ribeiro, G.L. (2008) Poder, redes e ideologia no campo do desenvolvimento. Novos estudos, 80, 109-125. 
Ulrich, D., \& Smallwood, N. (2009) Organization is not structure but capability. In Hesselbein, F., Goldsmith, M. (cords.) The organization of the future: visions, strategies and insights on managing a new era. San Francisco: Jossey-Bass.

Vázquez, M. A.(2006) Marketing social corporativo. Edición electrónica. Recuperado em: 25 nov.2014, de: www.eumed.net/libros/2006/mav/.

Vergara, S. C. (2008) Métodos de pesquisa em Administração. (3.ed.) São Paulo: Atlas.

WalMart (2015) Fair trade coffee. Recuperado em: 9 dez.2009, de: www.sustainableisgood.com/products/2008/04/walmartcoffee.html.

Wasan, P.G., \& Tripathi, G. (2015) Revisiting social marketing mix: a socio-cultural perspective. Journal of Services Research, 14 (2), 127-144.

Wielechowski, M., \& Roman, M. (2012) The essence of fair trade and its importance in the world economy. Oeconomia, 11 (4), 47-57.

Witkowski, T. H. (2005) Fair trade marketing: an alternative system for globalization and development. Journal of marketing theory and practice, 12 (4), 22-33.

Zenone, L. C. (2006) Marketing Social. São Paulo: Thomson.

Recebido em: 23/06/2015

Publicado em: 21/12/2015 